\title{
Misclassification of iodine intake level from morning spot urine samples with high iodine excretion among Inuit and non-Inuit in Greenland
}

\author{
Stig Andersen ${ }^{1,2,3 *}$, Rasmus Waagepetersen ${ }^{4}$ and Peter Laurberg ${ }^{1,5}$ \\ ${ }^{1}$ Arctic Health Research Centre, Institute of Clinical Medicine, Aalborg University Hospital, Hobrovej 18-22, \\ 9000 Aalborg, Denmark \\ ${ }^{2}$ Department of Internal and Geriatric Medicine, Aalborg University Hospital, Aalborg, Denmark \\ ${ }^{3}$ Department of Internal Medicine, Queen Ingrids Hospital, Nuuk, Greenland \\ ${ }^{4}$ Department of Mathematical Sciences, Aalborg University, Aalborg, Denmark \\ ${ }^{5}$ Department of Endocrinology, Aalborg University Hospital, Aalborg, Denmark \\ (Submitted 27 September 2014 - Final revision received 28 January 2015 - Accepted 6 February 2015 - First published online 8 April 2015)
}

Abstract

Iodine nutrition is commonly assessed from iodine excretion in urine. A $24 \mathrm{~h}$ urine sample is ideal, but it is cumbersome and inconvenient. Hence, spot urine samples with creatinine to adjust for differences in void volume are widely used. Still, the importance of ethnicity and the timing of spot urine samples need to be settled. We, thus, collected 104 early morning spot urine samples and $24 \mathrm{~h}$ urine samples from Inuit and non-Inuit living in Greenland. Diet was assessed by a FFQ. Demographic data were collected from the national registry and by questionnaires. Iodine was measured using the Sandell-Kolthoff reaction, creatinine using the Jaffe method and para-amino benzoic acid by the HPLC method for the estimation of completeness of urine sampling and compensation of incomplete urine samples to $24 \mathrm{~h}$ excretion. A population-based recruitment was done from the capital city, a major town and a settlement $(n 36 / 48 / 20)$. Participants were seventyeight Inuit and twenty-six non-Inuit. The median $24 \mathrm{~h}$ iodine excretion was 138 (25th-75th percentile $89-225) \mu \mathrm{g} / 97(25$ th-75th percentile $72-124) \mu \mathrm{g}$ in Inuit/non-Inuit $(P=0 \cdot 030)$, and $153(25$ th -75 th percentile $97-251) \mu \mathrm{g} / 102(25$ th-75th percentile $73-138) \mu \mathrm{g}(P=0 \cdot 026)$ when including compensated iodine excretion. Iodine excretion in $24 \mathrm{~h}$ urine samples increased with a rising intake of traditional Inuit foods $(P=0 \cdot 005)$. Iodine excretion was lower in morning spot urine samples than in $24 \mathrm{~h}$ urine samples $(P<0 \cdot 001)$. This difference was associated with iodine intake levels $(P<0 \cdot 001)$, and was statistically significant when the iodine excretion level was above $150 \mu \mathrm{g} / 24 \mathrm{~h}$. In conclusion, the iodine intake level was underestimated from morning spot urine samples if iodine excretion was above the recommended level.

Key words: Iodine excretion: $24 \mathrm{~h}$ urine: Spot urine: Creatinine adjustment: Urine collection timing: Ethnicity: Greenland Inuit

Iodine excretion is commonly assessed by the analysis of urine. A $24 \mathrm{~h}$ urine sample is ideal, but it is difficult to obtain complete and accurately timed collections, and compliance with $24 \mathrm{~h}$ urine sampling is often low ${ }^{(1,2)}$. Hence, spot urine samples are frequently used because they are simple to collect and pose minimal inconvenience to the subjects. However, concentrations in spot urine samples fluctuate with fluid intake, and creatinine adjustment is often used as an internal standard ${ }^{(3-8)}$ to compute an estimated $24 \mathrm{~h}$ iodine excretion.

Marked variations in estimated $24 \mathrm{~h}$ iodine excretion have been described between days ${ }^{(3,9)}$. This was suggested to relate to variations in iodine content of the diet. Furthermore, the iodine content of spot urine samples may vary with the time of collection $^{(10)}$, and this was speculated to relate to timing of meals. This is in keeping with early studies of iodine metabolism in humans that showed a fast appearance of the ingested iodine in blood and a subsequent appearance in urine ${ }^{(11)}$.

The traditional Inuit diet comprises fish and marine mammals that are rich in iodine ${ }^{(12)}$. The iodine nutrition survey of Greenland has shown that a high frequency of intake of the traditional Inuit diet is associated with a high iodine content of spot urine samples ${ }^{(13)}$. The iodine content of spot urine samples are used to calculate an estimated $24 \mathrm{~h}$ urinary iodine excretion (eUIE) by using ethno-specific creatinine excretions ${ }^{(14)}$. However, this needs to be validated.

The aim of the present study was to compare the $24 \mathrm{~h}$ urinary iodine excretion (UIE) with iodine excretion in morning spot

Abbreviations: eUIE, estimated $24 \mathrm{~h}$ urinary iodine excretion; PABA, para-aminobenzoic acid; UIC, urinary iodine concentration; UICC, ratio of urinary iodine concentration to creatinine concentration; UIE, urinary iodine excretion.

*Corresponding author: Dr S. Andersen, email stiga@dadlnet.dk 
urine samples, and to asses the influence of ethnicity. We, thus, collected spot urine samples and $24 \mathrm{~h}$ urine samples among Inuit and non-Inuit living in Greenland. We included para-aminobenzoic acid (PABA) as a marker of the completeness of $24 \mathrm{~h}$ urine collections ${ }^{(15)}$ and to allow us to compensate for incomplete $24 \mathrm{~h}$ urine collections ${ }^{(16)}$ using the HPLC-method ${ }^{(17)}$.

\section{Methods \\ Populations}

Participants were recruited from the general population in the capital city, Nuuk ( $n$ 36), in a major town in Greenland, Ilulissat ( $n$ 48), and in the settlement Saqqaq ( $n$ 20). The study population has been described in detail in the report on creatinine excretion in Inuit ${ }^{(14)}$. They were seventy-eight Inuit and twenty-six non-Inuit. The population in town and settlement was limited.

In Nuuk, we recruited a randomly selected subgroup of healthy participants of the population-based Greenland iodine nutrition survey ${ }^{(13)}$. In Ilulissat, participants in the survey of skeletal health $^{(18)}$ and seasonal variation ${ }^{(19)}$ collected a $24 \mathrm{~h}$ urine sample in addition to a spot urine sample. These subjects were included stratified by age, sex, ethnicity and residence. None took diuretics, thyroxine, none were treated for hypertension, and none had renal disease. None of the participants were pregnant.

Inuit ethnicity was defined by having both parents born in Greenland and mixed ethnicity if one parent was born outside Greenland. Participants were divided into Inuit (both parents born in Greenland) and non-Inuit (at least one parent born outside Greenland) for some calculations. Participants with both parents born in Denmark were classified as Caucasians.

The present study was conducted according to the guidelines laid down in the Declaration of Helsinki, and all procedures were approved by the Ethics Committee for Medical Research in Greenland. Participants gave written informed consent before participation.

\section{Procedures}

In Nuuk, participants were visited at home. They were given careful written and verbal instructions for $24 \mathrm{~h}$ urine collection by one of the investigational doctors (S. A.). They were asked to empty the bladder completely and then the $24 \mathrm{~h}$ urine collection was started. The void sample just before the initiation of the $24 \mathrm{~h}$ sample was collected to represent the spot urine sample.

In Ilulissat, participants came to the hospital, and in Saqqaq, they came to the nursing station for instruction and initiation of urine collection. The void sample before the initiation of the $24 \mathrm{~h}$ sample was collected to represent the spot urine sample. They were given careful written and verbal instructions (S. A., P. L.). They took the first $80 \mathrm{mg}$ of PABA, and were supplied with two additional doses of $80 \mathrm{mg}$ to be taken with main meals.

All participants were given a bag large enough to contain two 2-litre collecting plastic containers with a handle, a jug that fitted under the toilet seat and a funnel.
Participants were visited in their homes for the final urine collection $24 \mathrm{~h}$ after the initiation of the urine collection. They were asked if the collection was complete, and if they had encountered any problems with the urine collection.

Participants were given no restrictions of diet or daily living.

Volumes were estimated by weight assuming a gravity of $1 \mathrm{~g} / \mathrm{ml}$, and $5 \mathrm{ml}$ samples were stored at $-20^{\circ} \mathrm{C}$ until analysis.

A physical examination was performed by the investigational doctors (S. A., P. L.). It included height without shoes and weight in indoor clothing.

Information regarding age and sex was obtained from the National Civil Registration System, while information regarding lifestyle and dietary habits was obtained by questionnaires. Participants were interviewed by a Greenlandic interpreter or by one of the investigational doctors completing a questionnaire in either Danish or Greenlandic by participant choice. Questions were asked as written in the questionnaires.

The intake of Inuit diet was recorded by an interview-based FFQ as described in detail previously ${ }^{(13,19)}$. It included seven traditional Inuit food items (seal, whale, wild fowl, fish, reindeer, musk ox and hare) and seven imported food items (pre-cooked meals, potatoes, vegetables, butter, cheese, egg and fresh fruit). These had been selected because they were typical to the diet in Greenland and they have been used previously. Frequencies were given in six categories from never to daily. Inuit food items scored positively and imported food items scored negatively. The sum of food frequency score for all food items consumed by each participant was calculated based on this recording, and participants were categorised into groups of intake of $<40,40-60$ and $>60 \%$ traditional Inuit food item scores on a scale where $100 \%$ was purely Inuit foods and $0 \%$ was purely imported food. In addition, participants were asked how many days of the week the main meal was of Greenlandic food items and the number of days it was imported foods. This associated with the food frequency score ${ }^{(13,19)}$. Also, food frequency scores were validated by iodine as a biomarker of the intake of traditional Inuit foods ${ }^{(13)}$. Iodine was used as a biomarker of the intake of traditional Inuit foods as these are of marine origin and have been confirmed to be particularly rich in iodine $\mathrm{e}^{(12)}$.

\section{Para-aminobenzoic acid}

PABA (supplied by Unikem A/S) was used as a marker of completeness of urine collection. Its use is based on recovery in the urine of three $80 \mathrm{mg}$ doses taken with meals ${ }^{(15,20)}$. It was used among sixty-five participants in Ilulissat and Saqqaq. The first dose of PABA was taken in the clinic at the start of urine collection, and the subsequent two doses were taken with main meals. Urine samples containing less than $78 \%$ of PABA $(187 \mathrm{mg} / 24 \mathrm{~h})$ were designated incomplete as this was the level in single observations when $240 \mathrm{mg}$ (three times $80 \mathrm{mg}$ ) of PABA were taken and the HPLC method was used for analysis ${ }^{(17)}$.

One participant excreted only $32 \%$ of the expected ingested dose and stated to have missed one of the three PABA doses. Two individuals had very low PABA recovery $(3.9,5.4 \%$ ) despite collection of expected urine volumes (2692, $1766 \mathrm{ml})$. 
This suggested missing intake of PABA and they were excluded from the PABA compensations as recommended ${ }^{(16)}$. If PABA was below $187 \mathrm{mg} / 24 \mathrm{~h}$ (78\%), urine samples were considered incomplete. In such incomplete urine collections, iodine was compensated up to $93 \%$ as recommended if the PABA excretion was above $120 \mathrm{mg} / 24 \mathrm{~h}^{(16,17)}$.

\section{Assays}

Urine samples were analysed for PABA by the HPLC method as described in detail previously ${ }^{(17)}$. Urinary creatinine was measured by a kinetic Jaffé method ${ }^{(21)}$. Iodine was measured by the Sandell-Kolthoff reaction as described in detail previously $^{(13,22)}$

Iodine concentration in the $24 \mathrm{~h}$ urine samples $(\mu \mathrm{g} / \mathrm{l})$ was multiplied by urine volume collected to yield the UIE $(\mu \mathrm{g} / 24 \mathrm{~h})$. Iodine excretion in spot urine was expressed as concentration in spot urine samples (urinary iodine concentration; UIC, $\mu \mathrm{g} / \mathrm{l})$, as a ratio of $\mu \mathrm{g}$ iodine per $\mathrm{g}$ creatinine (I/creatinine) (UICC), and as an estimated $24 \mathrm{~h}$ UIE (eUIE) by stratifying $\mathrm{I} /$ creatinine ratio for age, sex and origin-specific creatinine excretions $^{(14)}$

Urine sample volumes were standardised to a $24 \mathrm{~h}$ collection time by dividing the volume by the actual collection time and multiplying by 24 . The actual urine collection times varied between 23.2 and $24 \mathrm{~h}$ except a single sample of $17 \mathrm{~h}$.

\section{Statistical analysis}

Results are given as medians with 25 th and 75 th percentiles. UIE in groups were compared using non-parametric statistics: Wilcoxon signed-rank test for paired comparisons of UIE in the same individual, Mann-Whitney $U$ test for unpaired comparison of two groups, Kruskal-Wallis test for comparing several groups and Kendall's $\tau$ for the relation between groups. Proportions were compared using $\chi^{2}$ test. The difference between iodine in $24 \mathrm{~h}$ urine samples (UIE, $\mu \mathrm{g} / 24 \mathrm{~h}$ ) and in spot urine samples (UIC, $\mu \mathrm{g} / \mathrm{l}$ ) was computed (UIE - UIC), and the deviations from zero among the differences between $24 \mathrm{~h}$ urine sample iodine (UIE) and the spot urine iodine measurements (UIC) was tested using the one-sample Kolmogorov-Smirnov test. The different measures of iodine in urine were compared as they are all used to portray the iodine nutrition by the same unit $(\mu \mathrm{g})$. Further, a linear regression provided an excellent fit of ln-transformed spot urine given ln-transformed $24 \mathrm{~h}$ urine. Based on this linear regression, optimal predictions and $95 \%$ prediction intervals were obtained for ln spot urine. Finally, these predictions and prediction intervals were back transformed to obtain predictions and prediction intervals for the difference between spot urine and $24 \mathrm{~h}$ urine illustrated in Fig. 1. The correlations between differences in iodine excretion estimates and iodine level in $24 \mathrm{~h}$ urine samples were tested using Spearman's $\rho$. The distribution was positively skewed, and for multiple linear regression analysis UIE data were ln-transformed (one-sample Kolmogorov-Smirnov test for normal distribution before/after ln-transformation: $P=0 \cdot 002 / 0 \cdot 93)$. Linear regression models were then used with ln-transformed UIE entered as dependent

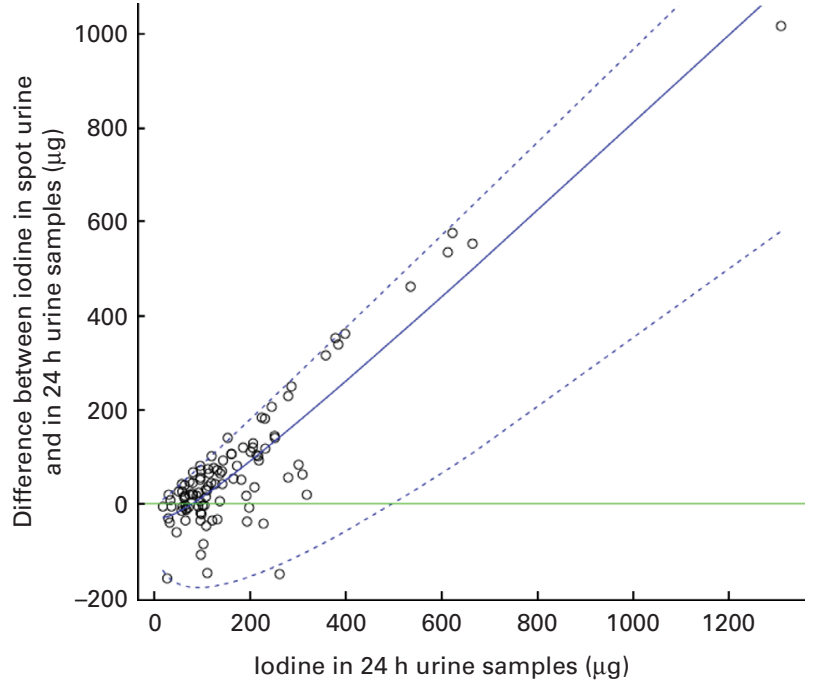

Fig. 1. Difference between iodine excretion in morning spot urine samples and $24 \mathrm{~h}$ urine samples plotted against $24 \mathrm{~h}$ urinary iodine excretion. The difference increased with rising $24 \mathrm{~h}$ iodine excretions. Negative values appeared when the $24 \mathrm{~h}$ urinary iodine excretion was below $250 \mu \mathrm{g}$, became frequent below $200 \mu \mathrm{g} / 24 \mathrm{~h}$, and the association lost statistical significance in correlation analysis when the $24 \mathrm{~h}$ iodine excretion level was below $150 \mu \mathrm{g}$. lodine concentration in the $24 \mathrm{~h}$ urine samples (UIC, $\mu \mathrm{g} / \mathrm{l}$ ) was multiplied by urine volume collected to yield the urinary iodine excretion (UIE, $\mu \mathrm{g} / 24 \mathrm{~h}$ ). lodine excretion in spot urine was expressed as concentration in spot urine samples (UIC, $\mu \mathrm{g} / \mathrm{l}$ ). The solid line shows the optimal prediction of the difference between the iodine excretion in morning spot urine samples and $24 \mathrm{~h}$ urine samples given the iodine in the $24 \mathrm{~h}$ urine samples. The dashed blue lines show $95 \%$ prediction intervals. The predictions and prediction intervals are based on a linear regression of In-transformed iodine data. This explains the non-linear shape of the curves. A colour version of this figure can be found online at http://www.journals.cambridge.org/bjn

variable. Independent variables entered for adjusted comparisons were age, sex, origin, diet and weight. Random selection of participants in Nuuk was performed using MedStat (Astra). Data were processed and analysed using Corel Quattro Pro 8 (Corel Corporation) and the Statistical Package for the Social Sciences version 13.0 (SPSS, Inc.). A $P$ value less than 0.05 was considered significant.

\section{Results}

Table 1 lists participant characteristics. Participant inclusion in Ilulissat and Saqqaq was based on stratification according to age, sex and ethnicity. Non-Inuit were included in the town only. Non-Inuit were taller $(P<0.001)$ and heavier $(P=0.001)$ than Inuit, but Inuit and non-Inuit had similar BMI. More Inuit than non-Inuit were smokers $(P=0.004)$, and Inuit had a more frequent intake of traditional Inuit food items $(P<0 \cdot 001$; Table 1$)$

\section{Para-aminobenzoic acid check}

Incomplete $24 \mathrm{~h}$ urine collection was suggested in twenty-six out of sixty-five $(40 \%)$ of the $24 \mathrm{~h}$ urine samples in Ilulissat that used the PABA check, as the excretion was below $187 \mathrm{mg} / 24 \mathrm{~h}$. Of the $24 \mathrm{~h}$ urine samples collected, twelve (18\%) had a PABA excretion below $50 \%$ of the expected; fourteen urine samples (22\%) could be compensated. 
Table 1. Characteristics of participants in the study of iodine excretion in spot- and $24 \mathrm{~h}$ urine samples among Inuit and non-Inuit in Greenland ${ }^{\star}$

(Number of participants, or median values and 25th-75th percentiles)

\begin{tabular}{|c|c|c|c|c|c|}
\hline & Inuit† $(n)$ & Non-Inuitł $(n)$ & $\operatorname{Mix} \S(n)$ & All $(n)$ & $P \|$ \\
\hline Number of participants & 78 & 20 & 6 & 104 & \\
\hline Men & 43 & 13 & 1 & 57 & \\
\hline Women & 35 & 7 & 5 & 47 & \\
\hline Height $(\mathrm{cm})$ & & & & & $<0.001$ \\
\hline Median & 163 & 177 & 170 & 167 & \\
\hline 25th-75th percentiles & $158-179$ & $172-182$ & $163-173$ & $160-174$ & \\
\hline Weight (kg) & & & & & $<0.001$ \\
\hline Median & 71.4 & $84 \cdot 2$ & $70 \cdot 1$ & $72 \cdot 7$ & \\
\hline 25th-75th percentiles & $63.1-76.9$ & $71 \cdot 9-93 \cdot 6$ & $61 \cdot 7-80 \cdot 2$ & $65 \cdot 6-82.5$ & \\
\hline BMI $\left(\mathrm{kg} / \mathrm{m}^{2}\right)$ & & & & & NS \\
\hline Median & $26 \cdot 0$ & $26 \cdot 2$ & $25 \cdot 4$ & $26 \cdot 0$ & \\
\hline 25th-75th percentiles & $23 \cdot 1-29 \cdot 8$ & $23 \cdot 8-29 \cdot 6$ & $21 \cdot 2-28 \cdot 0$ & $23 \cdot 3-29 \cdot 6$ & \\
\hline Age groups & & & & & 0.033 \\
\hline $30-39$ & 24 & 10 & 5 & 39 & \\
\hline $40-49$ & 14 & 6 & 1 & 21 & \\
\hline $50-59$ & 27 & 3 & 0 & 30 & \\
\hline $60-69$ & 13 & 1 & 0 & 14 & \\
\hline Residence & & & & & $<0.001$ \\
\hline City & 35 & 1 & 2 & 36 & \\
\hline Town & 24 & 19 & 3 & 48 & \\
\hline Settlement & 19 & 0 & 1 & 20 & \\
\hline Traditional Inuit diet intake & & & & & 0.086 \\
\hline$<40 \%$ & 39 & 16 & 5 & 7 & \\
\hline $40-60 \%$ & 32 & 4 & 1 & 37 & \\
\hline$>60 \%$ & 7 & 0 & 0 & 60 & \\
\hline Days/weekף & & & & & $<0.001$ \\
\hline $0-2$ & 20 & 19 & 4 & 43 & \\
\hline $3-4$ & 31 & 1 & 1 & 33 & \\
\hline $5-7$ & 25 & 0 & 1 & 26 & \\
\hline Smokerף $\|^{* *}$ & & & & & 0.004 \\
\hline Never & 18 & 11 & 0 & 29 & \\
\hline Past & 9 & 3 & 0 & 12 & \\
\hline Present & 49 & 5 & 6 & 60 & \\
\hline
\end{tabular}

* The study population has been described in detail in the report on creatinine excretion ${ }^{(14)}$

† An individual whose both parents were born in Greenland.

$\ddagger$ An individual whose both parents were born outside Greenland.

$\S$ An individual who had one parent born in Greenland.

I| Inuit $v$. non-Inuit.

ๆ Information missing in two Inuit.

** Information missing in one non-Inuit.

The iodine excretions with the different PABA check levels are listed in Table 2. Differences between PABA groups were not statistically significant.

\section{lodine excretion}

Table 2 shows the iodine excretion in $24 \mathrm{~h}$ urine samples (UIE) and in spot urine samples (UIC). UIE was slightly higher in Inuit than in Caucasians. Iodine excretion was higher when it was compensated for incomplete urine collection according to the PABA check (excretions $<187$ but $>120 \mathrm{mg} / 24 \mathrm{~h}$ ). Thus, median UIE level rose from 173 (25th-75th percentile 64-286) to 234 (25th-75th percentile 91-413) $\mu \mathrm{g}$ in Inuit that were compensated ( $n$ 11) and from 95, 80-245 $\mu \mathrm{g}$ to $139,127-381 \mu \mathrm{g}$ in the three non-Inuit that were compensated (Inuit/non-Inuit; $P=0 \cdot 003 / \mathrm{NS}$ ). The UIE level was 153 , 97-251 $\mu \mathrm{g} / 24 \mathrm{~h}(n$ 69) in Inuit and $102,73-138 \mu \mathrm{g} / 24 \mathrm{~h}(n$ 25) in non-Inuit when including both the complete and the compensated $24 \mathrm{~h}$ urine samples (data not shown).

Iodine excretion in $24 \mathrm{~h}$ urine samples increased with a rising number of days with intake of traditional Inuit foods
(Table 2) in the direct comparison $(101 / 139 / 193 \mu \mathrm{g} / 24 \mathrm{~h}$; $P=0.002)$ as well as in the adjusted comparison $(P=0.005)$. Ethnicity did not influence UIE after adjustment for diet. Spot urine samples (UICC) were influenced by ethnicity $(P=0.002)$ and diet $(P=0.007)$ after correction for creatinine while not when comparing the crude iodine content (UIC) of spot urine samples in the multivariate analysis.

The $24 \mathrm{~h}$ UIE differed from crude iodine content in spot urine samples (UIE $v$. UIC; $119 \mu \mathrm{g} / 24 \mathrm{~h} v .74 \mu \mathrm{g} / \mathrm{l} ; P<0 \cdot 001$ ), iodine in spot urine samples after creatinine correction (UIE $v$. UICC; $119 \mu \mathrm{g} / 24 \mathrm{~h} v$. $78 \mu \mathrm{g} / \mathrm{g} ; \quad P<0.001)$ and estimated $24 \mathrm{~h}$ UIE (UIE $v$. eUIE; $119 \mu \mathrm{g} / 24 \mathrm{~h} v .100 \mu \mathrm{g} / 24 \mathrm{~h} ; P<0 \cdot 001$; Table 2). This difference is detailed in Table 3, and it increased with rising iodine excretion levels.

Fig. 1 shows that the magnitude of the difference between iodine excretion in $24 \mathrm{~h}$ urine samples and spot urine samples (UIE - UIC) paralleled the iodine excretion levels as evaluated from $24 \mathrm{~h}$ urine samples (UIE) (Spearman's $\rho=0 \cdot 7$; $P<0 \cdot 001)$. The difference decreased with lower UIE levels. Negative differences were seen in $7 \%$ of samples above $200 \mu \mathrm{g} / 24 \mathrm{~h}, 20 \%$ of samples between 150 and $200 \mu \mathrm{g} / 24 \mathrm{~h}$, 
Table 2. lodine excretion in $24 \mathrm{~h}$ urine samples and in spot urine samples

(Median values and 25th-75th percentiles)

\begin{tabular}{|c|c|c|c|c|c|c|c|c|c|}
\hline & \multirow[b]{3}{*}{$n$} & \multicolumn{2}{|c|}{$24 \mathrm{~h}$ Urine samples } & \multicolumn{6}{|c|}{ Spot urine samples } \\
\hline & & \multicolumn{2}{|r|}{$\mathrm{UIE}^{\star}(\mu \mathrm{g})$} & \multicolumn{2}{|r|}{ UIC† $(\mu \mathrm{g} / \mathrm{l})$} & \multicolumn{2}{|c|}{ UICC $¥(\mu \mathrm{g} / \mathrm{g})$} & \multicolumn{2}{|c|}{ eUIE§ ( $\mu \mathrm{g} / 24 \mathrm{~h})$} \\
\hline & & Median & 25th-75th percentiles & Median & 25th-75th percentiles & Median & 25th-75th percentiles & Median & 25th-75th percentiles \\
\hline $\begin{array}{l}\text { All participants } \\
\text { PABA excretion (mg/24h) }\end{array}$ & 104 & $119 \cdot 1$ & $80-213$ & $74 \cdot 0$ & $45-114$ & 77.9 & $56-125$ & $100 \cdot 2$ & $64-136$ \\
\hline$>187$ & 39 & 118.9 & $91-206$ & $76 \cdot 0$ & $49-111$ & $62 \cdot 3$ & $42-106$ & $96 \cdot 1$ & $60-126$ \\
\hline $120-186$ & 14 & 141.8 & $64-255$ & 74.5 & $37-132$ & $73 \cdot 8$ & $43-119$ & 104.9 & $70-149$ \\
\hline$<120$ & 12 & $98 \cdot 2$ & $65-123$ & 69.5 & $44-102$ & 74.9 & $55-109$ & 86.7 & $73-134$ \\
\hline Nuuk\| & 39 & $141 \cdot 0$ & $80-251$ & $75 \cdot 0$ & $40-130$ & $108 \cdot 7$ & $74-165$ & $100 \cdot 3$ & $64-180$ \\
\hline Inuit & 78 & $138 \cdot 0$ & $89-225$ & $75 \cdot 0$ & $44-120$ & 95.1 & $63-140$ & $101 \cdot 1$ & $69-139$ \\
\hline Mix & 6 & 84.0 & $51-153$ & $49 \cdot 0$ & $20-165$ & $55 \cdot 1$ & $31-113$ & NA & NAף \\
\hline Caucasians & 20 & 104.9 & $80-133$ & 72.5 & $50-92$ & $58 \cdot 2$ & $40-74$ & $92 \cdot 3$ & $56-116$ \\
\hline \multicolumn{10}{|l|}{ Men } \\
\hline Inuit & 43 & $136 \cdot 8$ & $92-227$ & 78.5 & $44-117$ & 92.4 & $58-119$ & $127 \cdot 0$ & $75-158$ \\
\hline Caucasians & 13 & $107 \cdot 9$ & $76-172$ & $78 \cdot 0$ & $54-91$ & $51 \cdot 6$ & $36-72$ & $96 \cdot 1$ & $66-108$ \\
\hline \multicolumn{10}{|l|}{ Women } \\
\hline Inuit & 35 & $141 \cdot 0$ & $65-214$ & $70 \cdot 0$ & $43-130$ & $108 \cdot 7$ & $69-143$ & 83.0 & $58-124$ \\
\hline Caucasians & 7 & $102 \cdot 0$ & $80-119$ & $71 \cdot 0$ & $38-105$ & $62 \cdot 0$ & $40-114$ & $62 \cdot 6$ & $45-157$ \\
\hline \multicolumn{10}{|l|}{$\begin{array}{l}\text { Traditional Inuit diet } \\
<40 \%\end{array}$} \\
\hline Inuit & 39 & $139 \cdot 2$ & $64-218$ & 69.5 & $42-110$ & 89.9 & $65-139$ & $92 \cdot 7$ & $61-136$ \\
\hline Caucasians & 16 & 104.9 & $82-118$ & $72 \cdot 5$ & $55-92$ & $58 \cdot 2$ & $40-98$ & $98 \cdot 3$ & $56-142$ \\
\hline \multicolumn{10}{|l|}{$40-60 \%$} \\
\hline Inuit & 32 & $129 \cdot 1$ & $93-212$ & $80 \cdot 5$ & $41-126$ & $91 \cdot 1$ & $57-121$ & $110 \cdot 2$ & $68-130$ \\
\hline Caucasians & 4 & $150 \cdot 9$ & $52-241$ & $63 \cdot 5$ & $41-98$ & $53 \cdot 1$ & $35-68$ & 74.0 & $56-106$ \\
\hline \multicolumn{10}{|l|}{$>60 \%$} \\
\hline Inuit & 7 & 227.5 & $97-301$ & $130 \cdot 0$ & $45-218$ & $251 \cdot 0$ & $120-256$ & 204.4 & $100-340$ \\
\hline Caucasians & 0 & NA & NA & NA & NA & NA & NA & NA & NA \\
\hline \multirow{2}{*}{\multicolumn{10}{|c|}{$\begin{array}{l}\text { Days/week }{ }^{\star \star} \\
0-2\end{array}$}} \\
\hline \multicolumn{7}{|l|}{$0-2$} & & & \\
\hline Inuit & 20 & $100 \cdot 9$ & $60-150$ & $55 \cdot 0$ & $32-125$ & $78 \cdot 3$ & $57-147$ & 88.7 & $59-187$ \\
\hline Caucasians & 19 & $102 \cdot 0$ & $80-119$ & 74.0 & $54-93$ & $57 \cdot 0$ & $40-74$ & 88.5 & $55-118$ \\
\hline \multicolumn{10}{|l|}{$3-4$} \\
\hline Inuit & 31 & $139 \cdot 2$ & $92-224$ & $68 \cdot 0$ & $40-110$ & $86 \cdot 5$ & $57-115$ & 83.9 & $59-128$ \\
\hline Caucasians & 1 & NA & NA & NA & NA & NA & NA & NA & NA \\
\hline \multicolumn{10}{|l|}{$5-7$} \\
\hline Inuit & 25 & 193.4 & $100-347$ & $91 \cdot 0$ & $65-211$ & $110 \cdot 6$ & $83-171$ & $123 \cdot 6$ & $89-154$ \\
\hline Caucasians & 0 & NA & NA & NA & NA & NA & NA & NA & NA \\
\hline
\end{tabular}

UIE, urinary iodine excretion; UIC, urinary iodine concentration; UICC, ratio of urinary iodine concentration to creatinine concentration; eUIE, estimated $24 \mathrm{~h}$ urinary iodine excretion; PABA, para-aminobenzoic acid; NA, not

applicable.
* $24 \mathrm{~h}$ UIE: concentrations multiplied by $24 \mathrm{~h}$ urine volume.

†Crude iodine content of spot urine samples.

$\ddagger$ lodine per creatinine in spot urine samples.

Estimated from age, sex and ethno-specific creatinine excretions ${ }^{(14)}$ in spot urine samples.

$\|$ Sampling in Nuuk did not include the PABA check.

I Uncertain creatinine excretion for mixed origin. 
$29 \%$ of samples between 100 and $150 \mu \mathrm{g} / 24 \mathrm{~h}, 37 \%$ of samples between 50 and $100 \mu \mathrm{g} / 24 \mathrm{~h}$, and in $75 \%$ of samples below $50 \mu \mathrm{g} / 24 \mathrm{~h}$. Spot urine iodine (UIC) was markedly lower than $24 \mathrm{~h}$ iodine excretion (UIE) when the $24 \mathrm{~h}$ iodine excretion (UIE) was above $150 \mu \mathrm{g}$. The correlation between $24 \mathrm{~h}$ iodine excretion (UIE) and the difference between spot urine and $24 \mathrm{~h}$ urine iodine excretion (UIE - UIC) was nonsignificant when the $24 \mathrm{~h}$ UIE was below $150 \mu \mathrm{g}$.

Misclassification of iodine excretion occurred in $11 \%$ when the $24 \mathrm{~h}$ UIE was below $150 \mu \mathrm{g}$, and misclassification occurred in $72 \%$ when UIE was above $150 \mu \mathrm{g}(P=0 \cdot 03)$. These numbers were similar for spot urine iodine content (UIC), iodine:creatinine ratio (UICC) and estimated $24 \mathrm{~h}$ iodine excretion (eUIE).

\section{Discussion}

We reported a systematic collection of $24 \mathrm{~h}$ urine samples among Inuit and non-Inuit in Greenland. The use of the PABA check provided a reliable new insight into the importance of Inuit ethnicity for iodine excretion. Furthermore, measurement of iodine in $24 \mathrm{~h}$ urine samples and the use of the validated urinary creatinine excretion ${ }^{(14)}$ data indicated that spot urine samples should not be collected as morning urine samples among populations with an iodine intake above the level recommended by the WHO as misclassification of iodine excretion was frequent with high iodine intake levels.

It is cumbersome to collect $24 \mathrm{~h}$ urine samples and the PABA check suggested that $40 \%$ of the collections in the present study were incomplete. This number is similar to previous findings ${ }^{(16)}$, and it illustrates the consequences of the difficulties in obtaining complete and accurately timed urine collections. Also, it emphasises the low compliance with $24 \mathrm{~h}$ urine sampling. Thus, spot urine samples are a mainstay in everyday clinic and in population studies unless a check for completeness of $24 \mathrm{~h}$ sampling, such as the PABA check, is used to validate and possibly compensate the findings.

We included the PABA check and measured PABA using the HPLC method ${ }^{(17)}$. This method eliminates the risk of interference from aromatic amines from drugs such as sulphonamides and paracetamol that are co-determined when using the colorimetric method $^{(15,17)}$. This contributed to the validity of our findings.

Creatinine concentration in casual urine sample is often used to standardise substance excretion in urine. The WHO recommendations on the assessment of iodine nutrition are based on iodine content of spot urine samples as correction for creatinine excretion is considered unreliable when protein intake is low ${ }^{(23)}$. Protein depletion accounts for populations in third world countries, but is rare in populations elsewhere. Correction for creatinine reduced variation in iodine excretion by $40 \%{ }^{(3)}$, reduced the number of samples need by $20 \%{ }^{(6)}$, and increased the reliability of studies of iodine nutrition ${ }^{(6)}$ as confirmed in other populations ${ }^{(24)}$ and after iodine fortification ${ }^{(25)}$. Thus, stratification according to factors important to creatinine such as age and sex has improved the validity of this adjustment ${ }^{(7)}$, and adjusting for creatinine excretion is commonly adopted ${ }^{(26,27)}$. 
We recently showed that ethnicity influenced creatinine excretion by approximately $20 \%{ }^{(14)}$. Similarly, ethnicity has been reported to influence creatinine excretion among other groups. Thus, Blacks had a 5\% higher creatinine excretion per kilo body weight than Whites ${ }^{(28)}$ as was found among other people of African descent ${ }^{(29)}$, Pacific Islanders ${ }^{(30)}$ and other populations in South East Asia ${ }^{(31)}$. Thus, the creatinine adjustments among populations in Greenland should be stratified for ethnic origin in addition to age and sex to enhance the reliability of the correction.

The traditional Inuit hunter diet is rich in iodine ${ }^{(12)}$. This caused a high-normal iodine intake among populations in Greenland mainly living on the traditional diet ${ }^{(13)}$. It was reported as estimated $24 \mathrm{~h}$ UIE because correction for creatinine excretion reduces variation in iodine ${ }^{(3)}$ and hence increases the reliability of the estimated excretion ${ }^{(6,24,25)}$. The iodine nutrition survey in Greenland found a higher iodine intake level than what was suggested from the spot urine samples in the present study, but rather in resonance with the $24 \mathrm{~h}$ UIE. The cause for this discrepancy is described by the plot of the difference in iodine between spot urine and $24 \mathrm{~h}$ urine against the $24 \mathrm{~h}$ UIE. The increasing discrepancy with rising iodine intake levels are probably due to the fact that spot urine samples were collected in the morning hours in the present study. These urine samples thus reflect the iodine intake during late evening and night as iodine is excreted within a few hours after ingestion ${ }^{(9,11)}$. This extends the findings of a recent investigation that found a limited influence of time of spot urine samples ${ }^{(32)}$ into higher iodine intake levels and explains the lower iodine excretion in the morning urine also demonstrated earlier ${ }^{(10)}$. Hence, morning urine samples do not include the excretion of iodine from the main meals, which in Greenland may be very rich in iodine $^{(12)}$. The higher iodine excretion in the iodine nutrition survey in Greenland is most probably due to the fact that these spot urine samples were collected through all day and early evening and hence included iodine excreted after the main meals. The findings are likely to be similar when the excessive iodine intake is from drinking-water even though it may be consumed more evenly over the day as it is readily absorbed ${ }^{(8,11)}$.

The iodine excretion level about which the iodine intake estimation method was no longer markedly influenced by sampling hour was $150 \mu \mathrm{g} / \mathrm{d}$. This supports the reliability of the use of spot urine samples in studies of iodine deficiency while studies suggesting excessive iodine intake estimated from morning spot urine samples should be interpreted more cautiously as the true iodine intake level may be even higher than estimated from morning urine samples. Conversely, it may be suggested that if iodine excess is in focus, spot urine samples should not be collected during early morning hours.

Recent years have seen a focus on the importance of monitoring iodine intake levels in populations after iodine fortification ${ }^{(33)}$, in populations that are iodine replete ${ }^{(34)}$ and in populations with excessive iodine intake ${ }^{(35)}$. This is emphasised by the rising awareness of the possible adverse health consequences of an iodine intake at ${ }^{(36)}$ or above $e^{(37,38)}$ the recommended level. Our data imply that the use of morning spot urine samples may reduce the reliability of the estimated iodine intake levels in such populations as we found misclassification of iodine nutrition markedly more frequent at the higher iodine excretion level compared with the lower iodine excretion level. This finding was validated by the PABA check, which was measured using the more cumbersome HPLC method that reduced the risk of interference in the analysis.

In conclusion, early morning spot urine samples provide a useful classification of iodine nutrition when iodine deficiency is in focus. If iodine excretion is above the recommended level, then the iodine intake level is probably to be underestimated if spot urine samples are collected during early morning hours.

\section{Acknowledgements}

The authors thank Anne Marie Christensen at the hospital in Ilulissat for assisting in careful collection of $24 \mathrm{~h}$ urine samples in Ilulissat.

The present study was financially supported by grants from the Greenland Government and the Karen Elise Jensen foundation. The funders had no role in the design and analysis of the study or in the writing of the article.

The authors' contributions are as follows: S. A. involved in the conception of idea, study design, raising of funds, data collection, analysis and interpretation of the data, and writing of the manuscript; R. W. involved in the analysis and interpretation of the data, and reviewing of the manuscript; P. L. involved in the study design, collection of data, raising of funds, interpretation of the data and reviewing of the manuscript. All authors had full access to all of the study data, and took responsibility for the integrity of the data and the accuracy of the data analysis.

There are no conflicts of interest.

\section{References}

1. Garde AH, Hansen AM, Kristiansen J, et al. (2004) Comparison of uncertainties related to standardization of urine samples with volume and creatinine concentration. Ann Occup Hyg 33, 171-179.

2. Bingham SA \& Cummings JH (1985) The use of creatinine output as a check on the completeness of 24-hour urine collections. Hum Nutr Clin Nutr 39, 343-353.

3. Andersen S, Pedersen KM, Pedersen IB, et al. (2001) Variations in urinary iodine excretion and thyroid function. A 1-year study in healthy men. Eur J Endocrinol 144, 461-465.

4. Haddow JE, McClain MR, Palomaki GE, et al. (2007) Urine iodine measurements, creatinine adjustment, and thyroid deficiency in an adult United States population. J Clin Endocrinol Metab 92, 1019-1022.

5. Ohira S-I, Kirk AB, Dyke JV, et al. (2008) Creatinine adjustment of spot urine samples and $24 \mathrm{~h}$ excretion of iodine selenium, perchlorate, and thiocyanate. Environ Sci Technol 42, 9419-9423.

6. Andersen S, Karmisholt J, Pedersen KM, et al. (2008) Reliability of studies of iodine intake and recommendations for number of samples in groups and in individuals. $\mathrm{Br} \mathrm{J}$ Nutr 99, 813-818.

7. Vejbjerg P, Knudsen N, Perrild H, et al. (2009) Estimation of iodine intake from various urinary iodine measurements in population studies. Thyroid 19, 1281-1286. 
8. Andersen S, Pedersen KM, Iversen F, et al. (2008) Naturally occurring iodine in humic substances in drinking water in Denmark is bioavailable and determines population iodine intake. Br J Nutr 99, 319-325.

9. Rasmussen LB, Ovesen L \& Christiansen E (1999) Day-to-day and within-day variation in urinary iodine excretion. Eur J Clin Nutr 53, 401-409.

10. Als C, Helbling A, Peter K, et al. (2000) Urinary iodine concentrations follows a circadian rhythm: a study with 3023 spot urine samples in adults and children. J Clin Endocrinol Metab 85, 1367-1369.

11. Keating FR \& Albert A (1949) The metabolism of iodine in man as disclosed with the use of radioiodine. Rec Prog Horm Res 4, 429-481.

12. Andersen S, Hvingel B \& Laurberg P (2002) Iodine content of traditional Greenlandic food items and tap water in East and West Greenland. Int J Circumpolar Health 61, 332-340.

13. Andersen S, Hvingel B, Kleinschmidt K, et al. (2005) Changes in iodine excretion in 50-69-y-old denizens of an Arctic society in transition and iodine as a biomarker of the frequency of consumption of traditional Inuit foods. Am J Clin Nutr 81, 656-663.

14. Andersen S, Dehnfeld M \& Laurberg P (2015) Ethnicity is important for creatinine excretion among Inuit and Caucasians in Greenland. Scand J Clin Lab Invest 75, 44-50.

15. Bingham S \& Cummings JH (1983) The use of 4-aminobenzoic acid as a marker to validate the completeness of $24 \mathrm{~h}$ urine collections in man. Clin Sci 64, 629-635.

16. Johansson G, Bingham S \& Vahter M (1999) A method to compensate for incomplete 24-hour urine collections in nutritional epidemiology studies. Publ Health Nutr 2 , $587-591$.

17. Jakobsen J, Ovesen L, Fagt S, et al. (1997) Para-aminobenzoic acid used as a marker for completeness of 24 hour urine: assessment of control limits for a specific HPLC method. Eur J Clin Nutr 51, 514-519.

18. Andersen S, Boeskov E \& Laurberg P (2005) Ethnic differences in bone mineral density between Inuit and Caucasians in North Greenland are caused by differences in body size. J Clin Densitom 4, 409-414.

19. Andersen S, Jakobsen A \& Laurberg P (2013) Vitamin D status in North Greenland is influenced by diet and season: indicators of dermal 25-hydroxy vitamin $\mathrm{D}$ production north of the Arctic Circle. Br J Nutr 110, 50-57.

20. Williams DRR \& Bingham SA (1986) Sodium and potassium intakes in a representative population sample: estimation from $24 \mathrm{~h}$ urine collections known to be complete in a Cambridgeshire village. Br J Nutr 55, 13-22.

21. Bartels H, Bohmer M \& Heierli C (1972) Serum creatinine determination without protein precipitation. Clin Chim Acta 37, 193-197.

22. Laurberg P (1987) Thyroxin and 3,5,3'-triiodothyronine content of thyroglobulin in thyroid needle aspirates in hyperthyroidism and hypothyroidism. J Clin Endocrinol Metab 64, 969-974.
23. World Health Organization (2007) Assessment of Iodine Deficiency Disorders and Monitoring Their Elimination: A Guide for Programme Managers, 3rd ed. Geneva: WHO (WHO/UNICEF/ICCIDD).

24. König F, Andersson M, Hotz K, et al. (2011) Ten repeated collections for urinary iodine from spot samples or 24 hour samples are needed to reliably estimate individual iodine status in women. $J$ Nutr 141, 2049-2054.

25. Karmisholt J, Laurberg P \& Andersen S (2014) Recommended number of participants in nutrition studies are similar before and after an iodine fortification programme. Eur J Clin Nutr 53, 487-492.

26. Kesteloot H \& Joossens JV (1996) On the determinants of the creatinine clearance: a population study. J Hum Hypertens 10, 245-249.

27. Kampmann J, Siersbæk-Nielsen K, Kristensen M, et al. (1974) Rapid evaluation of creatinine clearance. Acta Med Scand 196, 517-520.

28. James GD, Sealey JE, Alderman M, et al. (1988) A longitudinal study of urinary creatinine and cretinine clearance in normal subjects. Am J Hypertens 1, 124-131.

29. Taylor EN \& Curhan GC (2007) Differences in 24-hour urine composition between black and white women. J Am Soc Nephrol 18, 654-659.

30. Eisner BH, Porten SP, Bechias SK, et al. (2010) The role of race in determining 24-hour urine composition in white and Asian/Pacific Islander stone formers. J Urol 183, 1407-1411.

31. Mente A, Honey RJD, McLaughlin JR, et al. (2007) Ethnic differences in relative risk of idiopathic calcium nephrolithiasis in North America. J Urol 178, 1992-1997.

32. Perrine CG, Cogswell ME, Swanson CA, et al. (2014) Comparison of population iodine estimates from 24-hour urine and timed-spot urine samples. Thyroid 24, 748-757.

33. Laurberg P, Jørgensen T, Perrild H, et al. (2006) The Danish investigation on iodine intake and thyroid disease, DanThyr: status and perspectives. Eur J Endocrinol 155, 219-228.

34. Andersen S, Iversen F, Terpling S, et al. (2012) Iodine deficiency influences thyroid autoimmunity in old age - a comparative population-based study. Maturitas 71, 39-43.

35. Teng W, Shan Z, Guan H, et al. (2006) Effect of iodine intake on thyroid diseases in China. N Engl J Med 354, 2783-2793.

36. Andersen S, Iversen F, Terpling S, et al. (2009) More hypothyroidism and less hyperthyroidism with sufficient iodine nutrition compared to mild iodine deficiency - a comparative population-based study of older people. Maturitas 64, 126-131.

37. Lv S, Xu D, Wang Y, et al. (2014) Goitre prevalence and epidemiological features in children living in areas with mildly excessive iodine in drinking-water. Br J Nutr 111, 86-92.

38. Teng X, Shan Z, Chen Y, et al. (2011) More than adequate iodine intake may increase subclinical hypothyroidism and autoimmune thyroiditis: a cross-sectional study based on two Chinese communities with different iodine intake levels. Eur J Endocrinol 146, 943-950. 